\title{
Improving Assessment in Dental Education Through a Paradigm of Comprehensive Care: A Case Report
}

\author{
Duncan D. Nulty, Ph.D.; Leonie M. Short, M.H.P.; Newell W. Johnson, F.Med.Sci., \\ Ph.D., F.D.S.R.C.S., F.R.C.Path.
}

Abstract: The assessment of clinical competence in health disciplines is a critical issue. Universities have a responsibility to graduate students who can demonstrate fitness to practice because clinical competence relates directly to the quality of patients' care - the quality of their treatment, their health outcomes, and their experience. In respect of the last of these, this article argues that the nature of what we term "clinical competence" ought to recognize the patient before the medical/dental condition or clinical intervention and, in order to achieve this, dental education should adopt learning, teaching, and assessment strategies that develop integrated learning outcomes consistent with a paradigm of comprehensive care. The article describes the ways in which this paradigm has been operationalized in the learning, teaching, and assessment strategies at Griffith University in Australia. It places a particular focus upon the assessment methods used in the Bachelor of Oral Health program. In this way, the article aims to illustrate ways that the quality of the assessment of clinical competence can, and should, be improved. While this is a work in progress, this description may be useful for educators at other academic dental institutions who wish to adopt, adapt, and develop similar approaches.

Dr. Nulty is Senior Lecturer, Griffith Institute for Higher Education, Griffith University; Ms. Short is Senior Lecturer, School of Dentistry and Oral Health, Griffith University; and Dr. Johnson is Professor, Griffith Institute of Health and Medical Research, and Foundation Dean, School of Dentistry and Oral Health, Griffith University. Direct correspondence and requests for reprints to Dr. Duncan D. Nulty, Griffith Institute for Higher Education, Griffith University, Mount Gravatt Campus, Mount Gravatt, Queensland, 4111 Australia; 61-7-373-56813 phone; 61-7-373-5998 fax; d.nulty@griffith.edu.au.

Keywords: clinical assessment, performance assessment, practice-based assessment, dental hygiene education, dental education

Submitted for publication 4/20/10; accepted 6/25/10

I n universities, the teaching, learning, and assessment of clinical skills occur in many disciplines, including medicine, nursing, dentistry, and oral health therapy. This article focuses on the last of these but has implications for the others, as well as for assessment practice more generally.

The assessment of clinical competence is a critical issue. Universities have a responsibility to graduate students who can demonstrate fitness to practice. ${ }^{1}$ This is because, in the health disciplines, clinical competence relates directly to the quality of patients' care - the quality of their treatment, their health outcomes, and their experience. In respect of the last of these, this article argues that the nature of what we term "clinical competence" ought to recognize the patient before the medical/dental condition or clinical intervention; it should adopt an approach of comprehensive care as its paradigm., ${ }^{2,3}$

The notion of comprehensive care has existed for at least forty years since the University of North Carolina hosted conferences on what it called " Comprehensive' Care in Clinical Dental Education" in 1969, 1975, and $1984 .{ }^{4}$ Compre- hensive care entails placing the patient at the center of considerations about the nature and form of interventions for their health, taking into account the full context of their lives. It therefore means that a student is responsible for the comprehensive assessment, treatment planning, provision of treatment, review, and revision of the treatment plan for and with a patient. ${ }^{5}$ Comprehensive care is a key feature of Cowpe et al.'s "profile and competencies," which should support the integration and merging of all disciplines to the benefit of dentists in training and also patients who are receiving treatment. ${ }^{6}$ What these authors mean by "profile" is a recognized dental practitioner who is a specific professional distinct from that of a medical practitioner. "Competencies" refer to a set of generic and subjectspecific knowledge, skills, and behaviors that enable graduating dentists to implement and promote appropriate oral health management plans to improve the general health of their patients. ${ }^{6}$ In dental education, comprehensive care is an approach to teaching, learning, and assessment in circumstances that approximate authentic general practice in dental 
practices in the United States, Canada, the United Kingdom, the European countries, and Australia. ${ }^{6-12}$

Perhaps unfortunately, traditional practice in dental schools has been to base the assessment of competence of clinical skills on the achievement of what are called "minimum graduation requirements," "minimal expected procedures," or "thresholds."13 While these discipline-driven numerical requirements in the clinical curriculum may result in competence for isolated or component procedures - particularly in respect of specific technical skills-it does not teach the student how to put it all together for the ultimate benefit of the patient. ${ }^{4}$ In other words, it creates an environment that places students' needs ahead of patients' needs. ${ }^{4}$

\section{Context}

Griffith University's School of Dentistry and Oral Health utilizes an educational approach in which all students' learning experiences are designed as authentically as possible to ensure the adoption of comprehensive care as the paradigm within which students learn. To operationalize this commitment, the faculty members in the School of Dentistry and Oral Health agreed to follow what were dubbed "The Ten Commandments for Curriculum Development." These were postulated in a document prepared by the foundation dean of the school in November 2005. ${ }^{14}$ This document explicitly set the foundations for the teaching and learning activities within the school (Figure 1).

These commandments reflect a commitment to particular values that guided the original design of the four programs offered by the school. These programs are the Bachelor of Oral Health in Dental Science, followed by the Graduate Diploma of Dentistry (which together comprise a five-year program leading to eligibility for registration as a general dental practitioner); the Bachelor of Oral Health in Dental Technology; and the Bachelor of Oral Health in Oral Health Therapy (in Australia, an oral health therapist is a dual-skilled dental hygienist and dental therapist who performs preventive dentistry for all ages as well as operative dentistry for children and adolescents). ${ }^{15,16}$ It follows that although each of these four programs has its own unique desired learning outcomes, the fact that the programs were all informed by the commandments (in a collegially academic not administratively driven way) meant that there were also desired learning outcomes that they had in common. Specifically, these are summarized under the following three broad headings:

1. Interprofessionality. The philosophy of the school is that students of dentistry, dental technology, and oral health therapy ought to learn together (mimicking professional practice) in an egalitarian way that allows the team to focus upon patient care and in a way that allows each member of the team to bring his or her expertise to bear as appropriate to the patient's health care needs. ${ }^{17,18}$ To that end, we have also published a review of the background literature that both justifies and outlines the Griffith University approach to interprofessional education (IPE) within our suite of programs. ${ }^{19}$

2. Comprehensive oral health care. This integrates four of the commandments: community service, prevention and health promotion, whole patient and family care, and quality of life issues. As a collective, these ideas together relate to a value orientation that seeks to broaden students' views beyond a simple focus on discipline-based technical competence in component procedures, toward instead an alignment of their thinking to a much broader and integrated range of considerations that, for example, include such matters as patient diversity.

3. Technical competence. This desired learning outcome has been deliberately positioned third instead of first because the philosophy of this school places it in a position that is subordinate to the higher ideals stated first. This is not meant to diminish the importance of technical competence, but rather to emphasize that technical competence alone is a necessary but not sufficient condition for excellence in clinical practice. Excellence, we argue, is characterized by practice that takes account of broader issues of interprofessionality and comprehensive care.

These desired learning outcomes for our students are driven by a collection of values relating to the nature of the educational provision in respect of the teaching and learning strategies employed. This accounts for the remainder of the commandments. The assessment, learning, and teaching provisions of this school are characterized by the following:

1. Scholarly informed assessment, learning, and teaching practices. This is characterized by the adoption of state-of-the-art pedagogical approaches that are themselves continually reviewed and informed by an evidence base that derives from ongoing audit of student and teacher skills and from research into educational processes; and 


\section{The Ten Commandments for Curriculum Development}

1. Interprofessionality: All members of the dental team are of equal value.

2. Community Service underpins all we do: within coursework, placements, research, clinical activity.

3. Whole Patient and Family Care is the responsibility of every clinician. Procedure-based teaching is kept to a minimum, consistent with acquisition of the necessary range of competencies.

4. Prevention and Health Promotion are top priorities in all courses.

5. The school will be research-lead $a b$ initio. Research data and attitude will underpin all teaching. This means all academics are expected to be research-active. The workload model will recognize that a teaching-research balance will differ among individuals, according to their skills and track records. Research into our educational processes is mandatory for all courses.

6. Evidence-Based Medicine and Clinical Audit approaches underpin all teaching.

7. Quality of Life issues are essential components of all interventions. These can be quantified and assessed. In essence, this is recognition of the primacy of patient perceptions in planning and evaluating care. It encompasses aesthetics, but not slavish pandering to cosmetics and fashion.

8. Technical Competence in treatments will be to the highest international standards, using the most modern methods and materials.

9. Learning and Teaching will employ state of the art pedagogical approaches. This encompasses a judicial balance of traditional teaching methods with student-centered learning and a wide range of teaching resources, including computer-aided and Internet resources.

10. Early Provision of Postgraduate Teaching is expected of all disciplines.

Figure 1. Griffiths University School of Dentistry and Oral Health's ten commandments for curriculum development

Source: Johnson NW. The ten commandments for curriculum development. Southport, Australia: Griffith University, November 2005.

2. Adoption of peer learning throughout all levels of the programs, whether student or teacher. This principle recognizes the significant learning value associated with peer learning-for example, through exposure to different professions (interprofessionality). This principle also underpins the programmatic commitment to promoting continuing professional development for its graduates.

\section{Teaching and Learning Strategy}

This section describes the approaches that have been taken to implement the curriculum design parameters above. To make that task manageable, this article focuses more explicitly on the Bachelor of Oral Health in Oral Health Therapy.

The structure of this three-year program is represented in Figure 2. The figure shows that students need to complete $4 \times 10$ credit point courses in each of six semesters ${ }^{20}$ spanning three years. The first year consists of eight foundation courses focussing on basic theory, plus a noncredit course that introduces students to the dental professions. The second year builds on these foundations, focusing on developing the knowledge and skills associated with preventive and operative dentistry. Courses include biochemistry, oral biology, general pathology, microbiology, and comprehensive oral health care. ${ }^{20}$ In the third year, students build further on the foundations in health science provided in the first and second years by completing courses in oral 


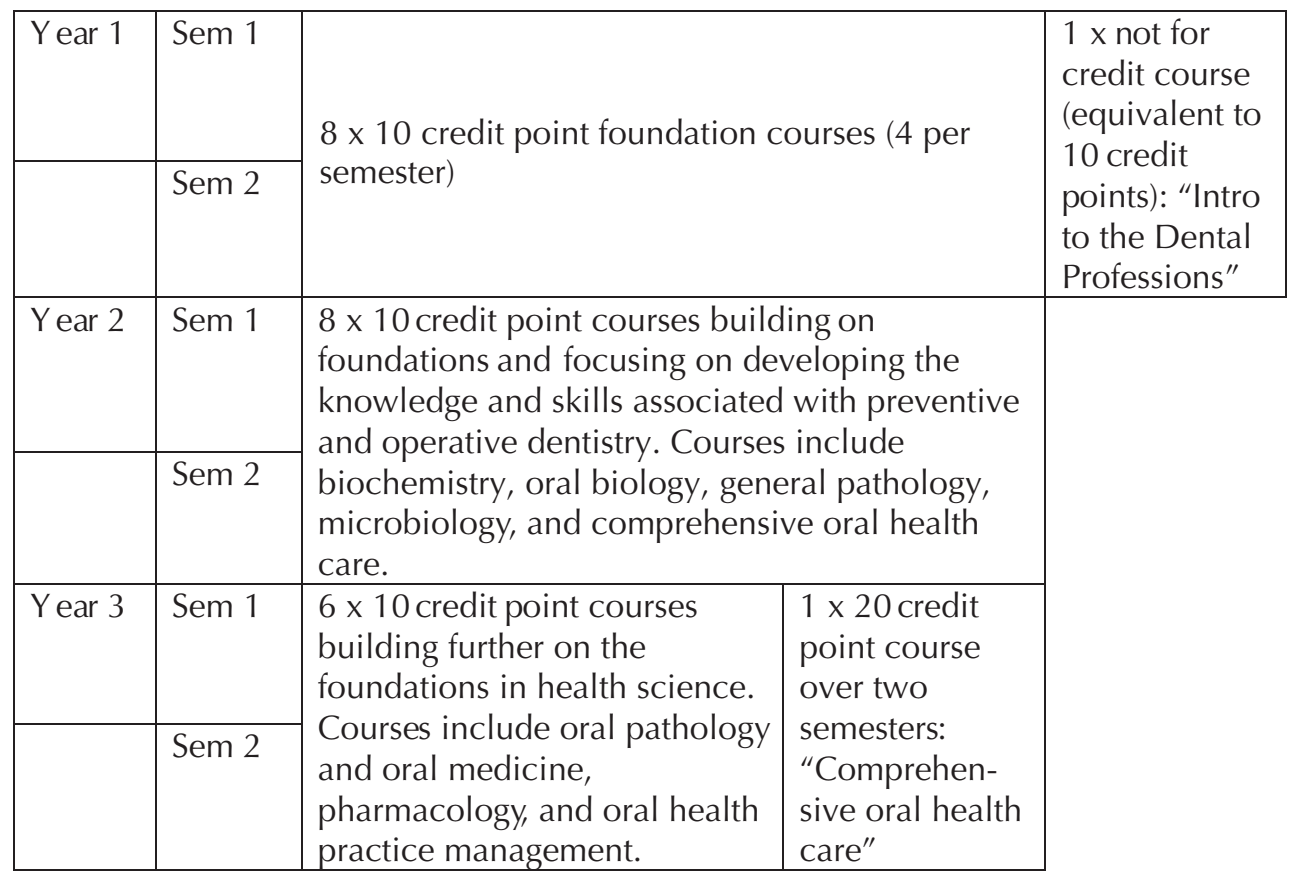

Figure 2. Program structure for the Bachelor of Oral Health in Oral Health Therapy

pathology and oral medicine, pharmacology, and oral health practice management. ${ }^{20}$ They also undertake a two-semester course in comprehensive oral health care, a capstone course with the role of putting it all together that focuses explicitly upon clinical skills development in the discipline of oral health therapy.

In direct alignment with the desired learning outcomes that are common to each of the school's programs, the following themes illustrate some of the particular learning and teaching strategies adopted.

Interprofessionality. Interprofessional education occurs when students from two or more professions learn about, from, and with each other to enable effective collaboration and improve health outcomes. ${ }^{21}$ It is achieved, in part, by having dental science, dental technology, and oral health therapy students study courses alongside each other, in the lecture theaters, simulation laboratories, and clinical settings. ${ }^{19}$ However, the overall goals are the development of graduates who have internalized the values implicit in the ten commandments and which are summarized under all three headings: interprofessionality, comprehensive oral health care, and technical competence. Assessment of student learning throughout the program is similarly informed by these values, thereby including assessments that do not solely, or excessively, focus on technical skill alone. (Examples of the ways we assess student learning outcomes appear below.)

Comprehensive oral health care. The approach outlined above to help develop interprofessionality also serves, in part, as an underpinning to the development of comprehensive oral health care. This is added to in a range of ways. For example, students are required to undertake a community research project commencing in the second semester of the first year and continuing for the remaining two and a half years of the program..$^{14,22,23}$ These projects involve multidisciplinary teams, in common with the general strategy of having students of different professions (dentistry, oral health therapy, and dental technology) study alongside each other in all parts of the program.

A second illustration is that students' learning is elaborated beyond what could otherwise be accomplished by requiring them to study in community settings and/or outplacements. For example, students are rostered to attend dental clinics located 
within the government's local primary school where they provide preventive and operative dentistry to school-age children. This activity broadens students' learning in several ways. First, it helps to develop their knowledge about the Queensland Government's Department of Health and Department of Education policies and practices. It also helps oral health therapy (and dental) students engage with the primary school students in health promotion activities. Thirdly, it exposes our clinical students to the communitybased realities of providing dental services. In this example, these realities include the primary school timetable that has to be considered; the possibility of liaison with general medical practitioners (if there is a medical history for a particular patient); complications arising because the patients are under age, necessitating consultations with parents; and referrals to specialists that may also need to be organized. Such community-based factors rarely arise within the confines of learning and teaching on the typical university/dental school campus. ${ }^{24}$

A third illustration of how students develop skills in comprehensive oral health care is through control over the selection and allocation of patients to students who are treated by them at Griffith University's main metropolitan dental clinic. Specifically, the patients that each student gets to see are not determined at random or by opportunity. Rather, there is a rigorous and deliberate process of allocation. First, patient needs are assessed by a general dental practitioner. This assessment is then used to match a patient to a student who has reached a particular point of his or her learning and is competent to assess and treat the patient. This allocation balances each student's competence and developmental needs. Thus, no student is allocated a patient whose dental needs are beyond his or her technical competence. At the same time, each and every student is allocated patients who have dental needs that the student is required to practice. Currently, patients are allocated to a team - or "practice" - of students of various seniorities. Within these teams, treatment planning tasks are allocated to individual students of appropriate skill level (vide infra). ${ }^{25}$

Technical competence. Students' technical competence is progressively developed and shaped over the three years of the program. Thus, in the first year, students learn about the dental professions and what it means to be a professional. In the second year, students undergo skills development in a dental simulation laboratory. In the second semester of the second year, students progress to treating their first (real) patients for assessment, treatment planning, and dental hygiene. In the third year, students continue to treat adult patients for dental hygiene as well as completing their training in pediatric dentistry and consequently completing courses of treatment for child and adolescent patients.

Although the above themes are presented separately, the development of students' skills in interprofessionality, comprehensive oral health care, and technical competence are integrated. The objective of the program overall is to produce an oral health professional who can put it all together by being able to independently and collaboratively practice evidence-based comprehensive care. ${ }^{3}$ This demonstration requires students to show a high degree of integration across a broad range of patients with various medical and dental needs, i.e., they need to demonstrate the reproducibility of their skills, regardless of the parameters of the presenting patient's problems. ${ }^{10}$

\section{Assessment of Student Learning}

The assessment of students' learning in this program recognizes that students' study behaviors and their learning outcomes are heavily influenced by the assessable tasks they are asked to complete. To that end, the selection, sequencing, and nature of these tasks (hereafter referred to simply as "assessment") are used as a mechanism to support the achievement of the curricular objectives detailed above. ${ }^{26}$ Practices for the assessment of student learning also have a quality assurance function. In this regard, they need to provide information that can credibly demonstrate to an interested public that particular learning outcomes have been achieved at particular points in the students' learning. ${ }^{26}$ One useful model that relates to these ideas is provided by Miller. ${ }^{27}$ Briefly, Miller proposed a "framework for clinical assessment," which recognizes that it is appropriate to assess different learning outcomes with different assessment methods in medical education. Several pertinent features of this multidimensional complex need to be highlighted (Figure 3).

First, the model captures the idea that there is a hierarchy of different kinds of learning outcomes that we may wish to assess. ${ }^{27}$ At the base of the pyramid is some assurance that a student knows what is required in order to carry out those professional functions effectively. The knowledge base is important and needs to be measured, but knowledge alone is not sufficient to appraise medical practice. Students must also show 


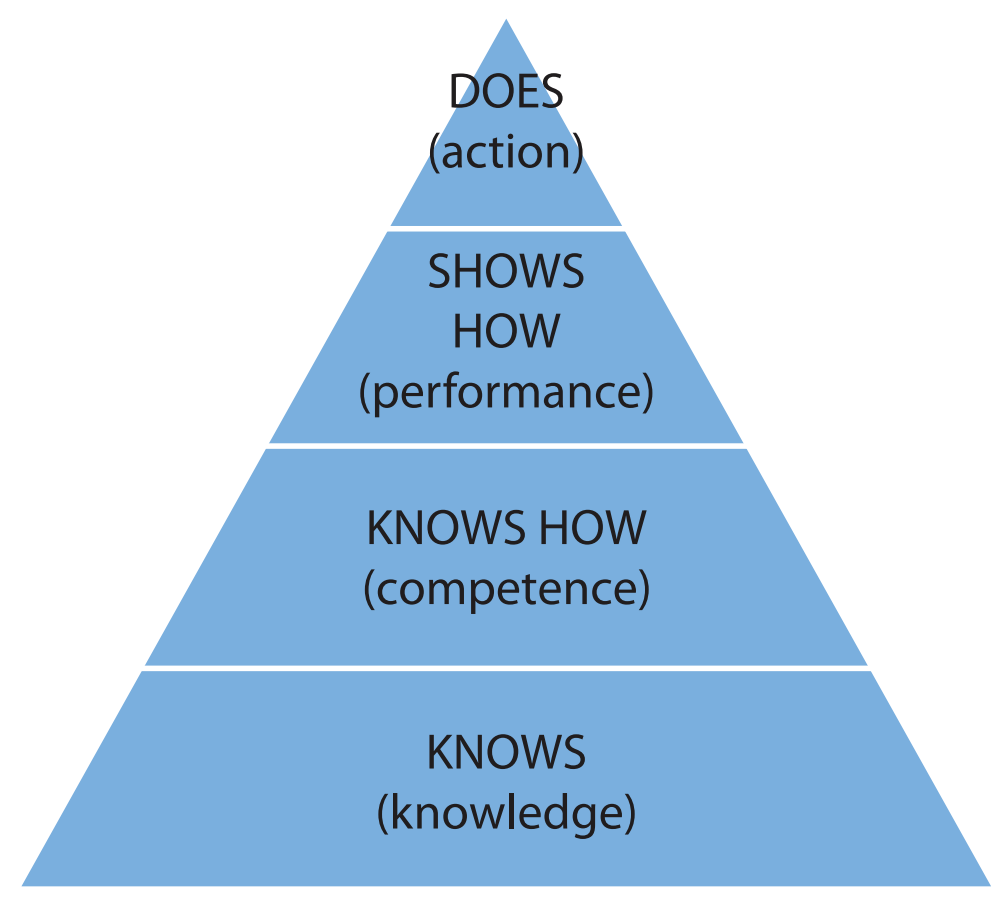

Figure 3. Framework for clinical assessment

Source: Reprinted with permission from Miller GE. The assessment of clinical skills/competence/performance. Acad Med 1990;65(9 Suppl):s63-s67.

what Miller called "competence" by knowing how to use the knowledge they have accumulated and by showing how they do it through "performance." Finally, the student needs to demonstrate the "action" component of professional behavior by doing or functioning independently in the real setting of clinical practice. As the dimensions become more complex or move apically, so does the professional authenticity of the clinical assessment. ${ }^{28}$

Secondly, the learning outcomes that are most highly valued are those at the top of the triangle or pyramid. It is toward the development of these outcomes that educational programs are ultimately directed. Furthermore, the learning outcomes of action and performance (at the apex) are developed constructively on a foundation of other learning outcomes that temporally tend to be developed first. In other words, excellence in performance of the learning outcomes higher in the hierarchy is (at least partly) dependent on mastery of those below. However, it should be noted that assessment of learning outcomes lower in the triangle (knowledge and competence) cannot be assumed to predict, either fully or with confidence, the achievement of the more complex goals higher up. ${ }^{27}$

Third, to assess the different kinds of learning outcome validly and rigorously requires the use of different assessment tools. For example, assessing performance skills cannot be validly and rigorously assessed using written reports or multiple-choice questions (MCQs). Rather, the use of simulated laboratory exercises and objective structured clinical examinations (OSCEs) is more appropriate. Wass et al. (Figure 4) have adapted Miller's framework for clinical assessment in medicine to focus on validity throughout the pyramid. ${ }^{26}$ This focus on validity means selecting and using tests that actually succeed in measuring facets of clinical competence that they were designed to test.

Finally, Miller's framework shows that these different kinds of assessment are used in different proportions. That finding is only problematic where the proportions do not reflect the value placed on the learning outcomes assessed. For example, if the use 


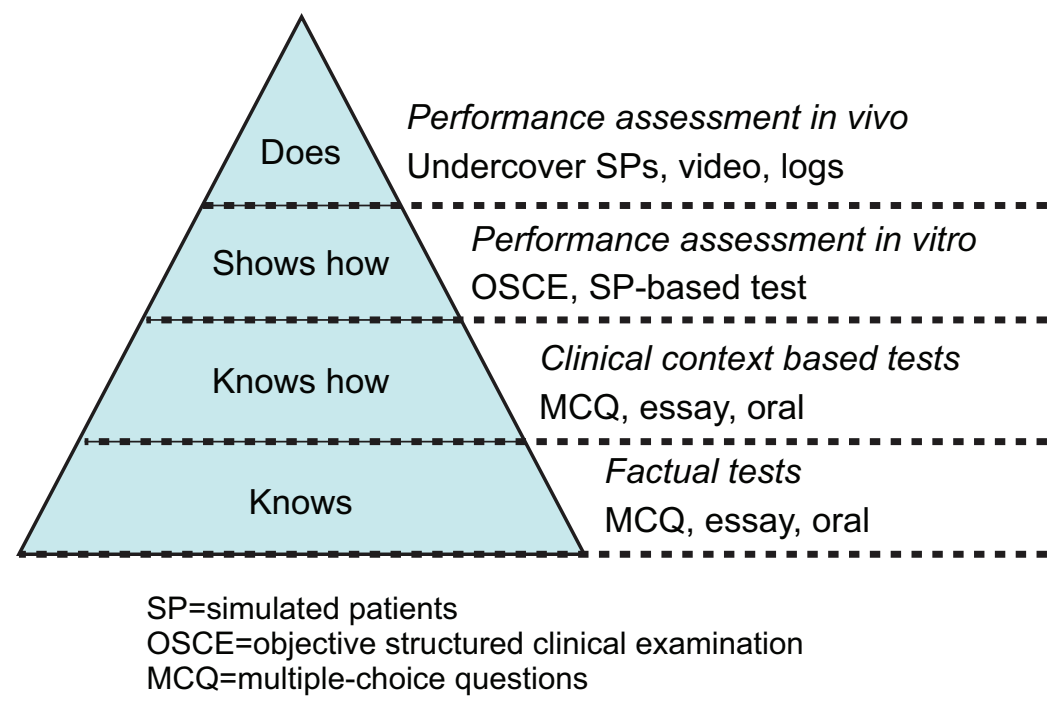

Figure 4. Wass et al.'s adaptation of Miller's framework for clinical assessment 2001;357(9260):945-9.

of factual tests, MCQs, and essays predominates, then the total amount of assessment of the higher order learning outcomes is minimal. Such a pattern could be inappropriate if the proportion of assessment of the higher learning outcomes is insufficient to total a thorough assessment of those outcomes. Unfortunately, that pattern is often what is seen in dental schools: the higher learning outcomes (the ones consistent with the achievement of competence in the sense of skills in the provision of comprehensive oral health care) are minimally assessed or are assessed using tools that do not make valid assessments of these outcomes.

\section{Assessment Practice in Dental Education at Griffith}

Doctoral research by Short has examined the oral health therapy program at Griffith University using the same model proposed by Miller. ${ }^{27}$ In 2009, there were five courses in which clinical skills in oral health therapy were taught and assessed. Of these, one was in the first year, two in the second year, and another two in the third year. The twenty-one assessment methods in these five courses included end of semester written exams, oral examinations, written assignments, practical assessments in the simulation laboratory, self-assessment of clinical skills in dental surgeries, an OSCE, and periodontal and pediatric clinical log books. Of the twenty-one assessments, 38.1 percent were classified as knowledge-based, 19 percent as competence-based, 28.6 percent as performance-based, and 14.3 percent as action-based (Figure 5). Interestingly, the majority of the assessments in the lowest level of the Miller framework were those shared with the more traditional disciplines in dentistry.

In 2008, the Task Force on Student Outcomes Assessment of the American Dental Education Association's Commission on Change and Innovation in Dental Education described the status of student outcomes assessment in dental education in the United States. ${ }^{29,30}$ Fifty-three of fifty-six (93 percent) dental schools were represented in their findings, summarized diagrammatically in Figure 6. Specifically, 931 course directors and academic affairs deans (approximately 45 percent response rate) indicated that the five traditional mainstays of student performance evaluation-multiple-choice testing (28 percent), 


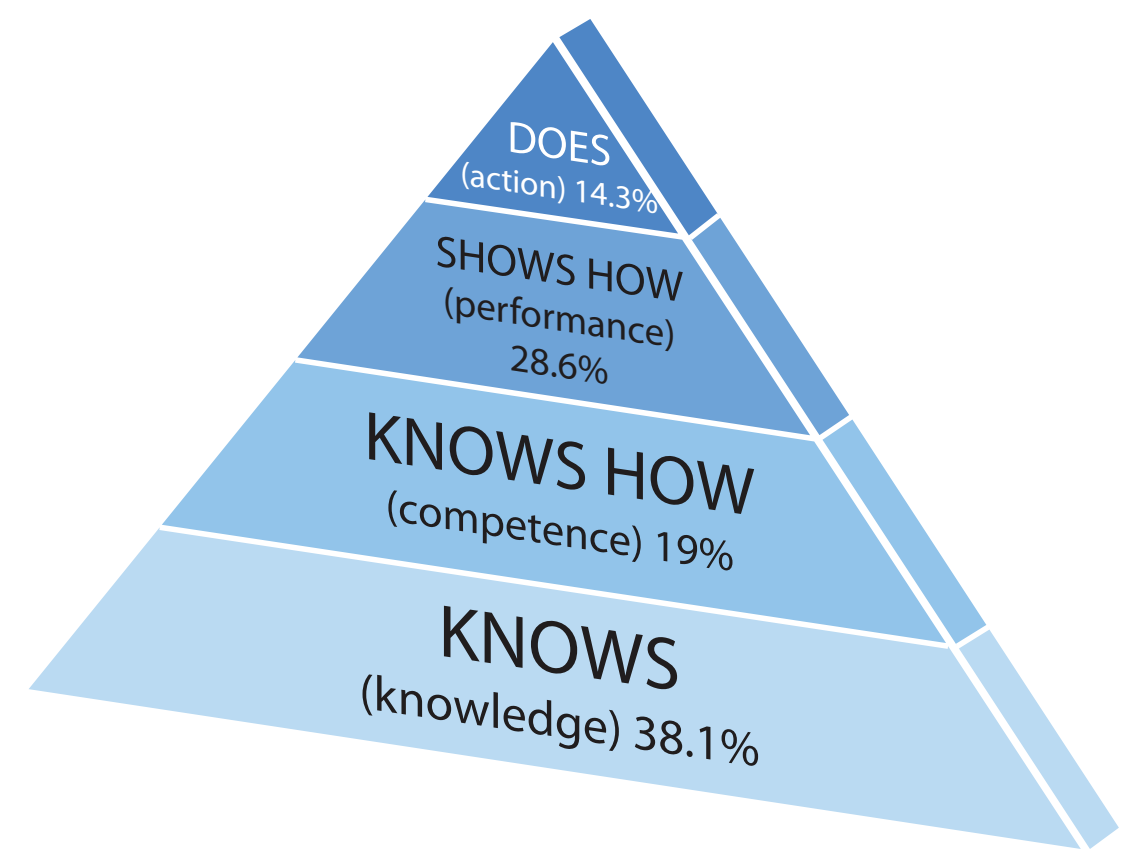

Figure 5. Assessment of clinical skills in oral health therapy at Griffith University in 2009

lab practicals ( 8 percent), daily grades (12 percent), clinical competency exams (11 percent), and procedural requirements ( 3 percent) - still comprise the primary assessment tools in dental education. ${ }^{29}$ Contrary to contemporary educational philosophies, most dental students have experienced the reality in which a semester-long or year-long course is followed by a single formal exam that constitutes the only measurement of student performance. ${ }^{31}$ A group of newer assessment techniques such as OSCE, critical appraisal task (CAT), portfolio, triple-jump exercise, chart-stimulated evaluation, and longitudinal/global evaluation are rarely employed (13 percent). ${ }^{29,32}$

What these data demonstrate is that the distribution of assessment tools targeting the assessment of clinical competence at Griffith University is not in line with current practices in predoctoral education in the United States. Moreover, it does not reflect the balance that we would like. As noted by Short et al., "Determining optimal strategies to assess students' capabilities at each of the four levels of the hierarchy, particularly at the apex of the pyramid, is an international challenge for all academics involved in dental education." 33
What follows briefly describes four initiatives for the assessment of clinical competence that have been started by different teams or course convenors within the School of Dental and Oral Health. These initiatives are currently in a relatively early state of development. However, each aims to contribute to an improvement in student performance and to an evaluation of whether, in fact, this has occurred. Findings from these initiatives will be the subject of future research articles.

Interprofessionality as a strategy for comprehensive care. In February 2009, the school introduced a novel concept of team-based treatment planning built around the Comprehensive Care Clinic (CCC). Students treat patients in the CCC from their third year of studies. Students are organized into clinical groups, each group consisting of one third-, one fourth-, and one fifth-year dental student (DS), as well as an oral health therapy (OHT) and a dental technology (DT) student. All patients are allocated to a student group after an initial screening in which the students review all patient data, agree on a treatment plan, and distribute the treatment procedures amongst the group according to the competence and expertise 


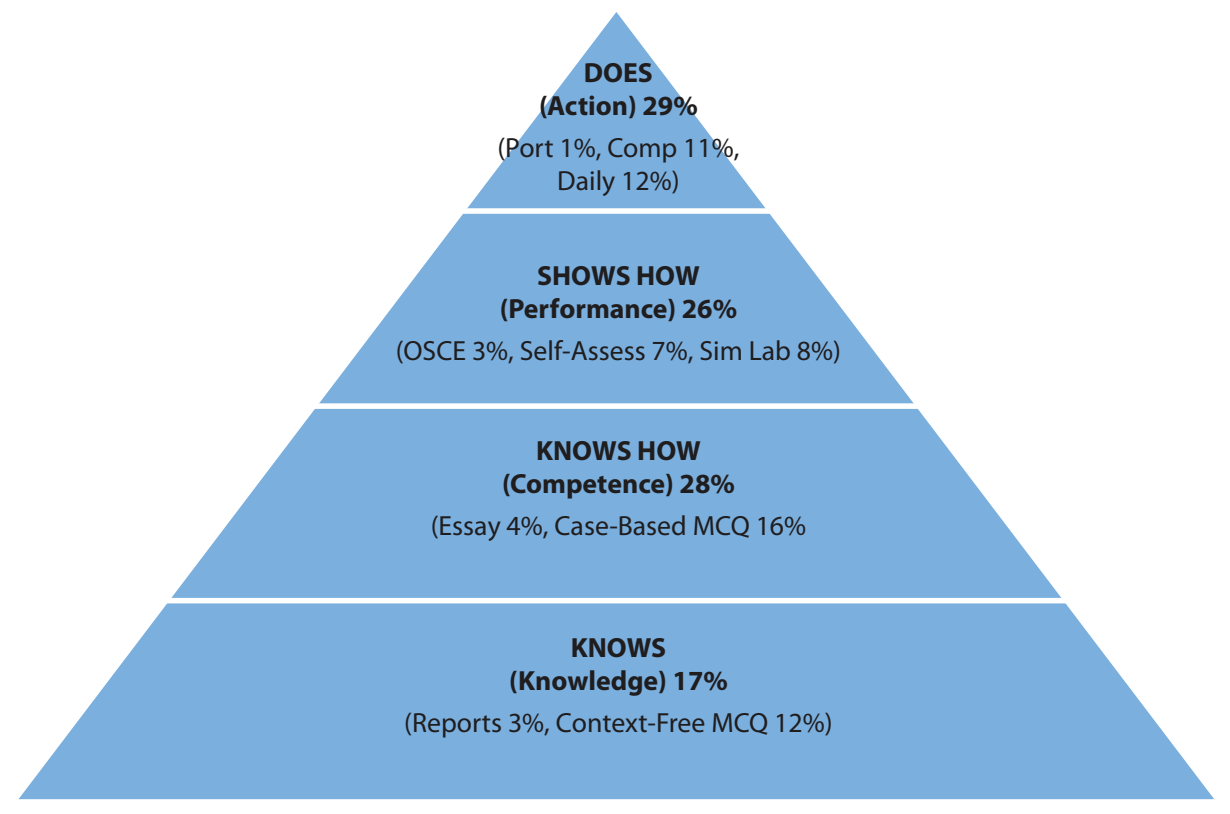

Figure 6. Student outcomes assessment by category in U.S. dental schools, 2008

Sources: Data from Albino JE, Young SK, Neumann LM, Kramer GA, Andrieu SC, Henson L, et al. Assessing dental students' competence: best practice recommendations in the performance assessment literature and investigation of current practices in predoctoral dental education. J Dent Educ 2008;72(12):1405-35; Young S, Albino J, Neumann L, Kramer G, Andrieu SC, Henson L, et al. What methods do dental school course directors use to assess students' progress toward competence? Selected results of the 2008 student competency assessment survey. Presentation at American Dental Education Association Commission on Change and Innovation in Dental Education Liaisons Summer Conference, June 23-25, 2008, Chicago, IL; and Hendricson WD. What methods do dental school course directors use to assess students' progress toward competency? Washington, DC: American Dental Education Association, 2008. At: www.adea.org/adeacci/Resources/Documents/Competency_Assessment_Findings-Hendricson.pdf. Accessed: November 23, 2009.

of each group member. ${ }^{25}$ This model aims to expose students to comprehensive treatment planning from an early stage and establish interpersonal and interprofessional collaboration.

Professional competence. For professional competence to be developed, formative assessment and feedback are key elements. However, there are reasons why clinical educators fail to give students effective feedback. Namely, assessment strategies may focus on performance at the expense of providing adequate feedback; scoring sheets may provide only limited space for feedback; clinical educators may not fully appreciate the role of feedback as a fundamental clinical teaching tool; and clinical educators may not be skilled in providing high-quality feedback. ${ }^{34}$ To counteract these difficulties, an innovative addition to the clinical sessions was introduced in the school in 2009. In the middle of semester 1, the course 3017DOH "Comprehensive Oral Health Care 2" in- cluded a weekly one-hour student-centered learning (SCL) session for the third-year OHT students. ${ }^{35}$ The students met with their clinical supervisor to discuss and share experiences with their clinical cases in a nonevaluative and nonjudgmental environment. ${ }^{34}$ Illustrative comments from students include these: "SCL times good to talk about clinical cases etc."; and "SCL sessions well done- - just to chat and talk about certain treatment and patient scenarios."

Standardized clinical competence assessment. At the start of 2009, the school's director of clinical operations met with the discipline leads, course convenors, and other educators to lead the development of standardized clinical competence assessment forms. These forms are now used for the assessment of dental science and oral health therapy students in Griffith University's dental clinic. Domains of "Authority to start" and "Professionalism" are assessed at every appointment at which some of 
the principles of comprehensive oral health care are included and assessed. (See Figure 7 for the principles assessed in Professionalism.) The standardized clinical competence assessment forms also contain adequate space for recording tutor feedback and student comments. This is consistent with Norcini's practice points for workplace-based assessment, which state that feedback is more effective if it is timely and specific, focuses on important aspects of the performance in the workplace, and is consistent with the needs of the learner. ${ }^{34}$

Introduction of OSCE in first-year clinical course. By describing this, we seek to illustrate how there is alignment between the assessment method for the desired learning outcomes and the overall values manifest in the school philosophy. To introduce students to assessment techniques that test higher levels of professional competence, innovative assessments were developed for 112 first-year dental science and oral health therapy students in 2009. The learning outcomes for the course included the following, amongst others: demonstrating a familiarity with the dental workplace; demonstrating appropriate infection control procedures; demonstrating an understanding of tooth morphology in the deciduous and permanent dentitions; and appraising patient rights and complaint procedures. Short introduced a clinical and laboratory log book for the first-year clinical course, 1005DOH "Introduction to Clinical Oral Health Practice." The log book included assessments of skills demonstrated in the simulation laboratory, prosthetic laboratory (tooth morphology), and dental clinic at Griffith University. A selfassessment of clinical skills was also included for outplacements to private general and specialist dental surgeries during the semester. Short further improved the assessment of students' performance by the inclusion of a more authentic twenty-station OSCE in the simulation laboratory (Figure 8). This took the place of an inauthentic examination comprised of multiple-choice and short-answer questions. ${ }^{29,36}$ These images illustrate the authenticity associated with the assessment of students' clinical competence via a twenty-station OSCE. Some tasks included in the OSCE, which further demonstrate the authenticity of this mode of assessment, were instruments used to conduct a dental examination, restorative materials mixed in an amalgamator, and the order of putting on personal protective equipment (PPE). Thus, the predicted benefit of an OSCE as an assessment method in this course is that it should actually succeed in testing facets of clinical competence that it was designed to test-within the overall values manifest in the school philosophy of interprofessionality, comprehensive

\section{Professionalism}
A. Demonstrated care and compassion
B. Maintained the integrity and confidentiality of patient records
C. Records were thorough and accurate
D. Explained the procedures and kept the patient/parents informed
E. Provided appropriate postoperative advice
F. Interacted with the staff in a professional manner
G. Punctual
H. Correct dress code
I. The student was willing to learn and accepted advice
J. Time management appropriate and treatment well planned
K. All equipment/materials ready for use before the appointment
L. Student well prepared and understood the procedures
M. Infection control procedures and clinic policies followed

Figure 7. Principles of professionalism assessed among dental science and oral health therapy students in the dental clinic at Griffith University 

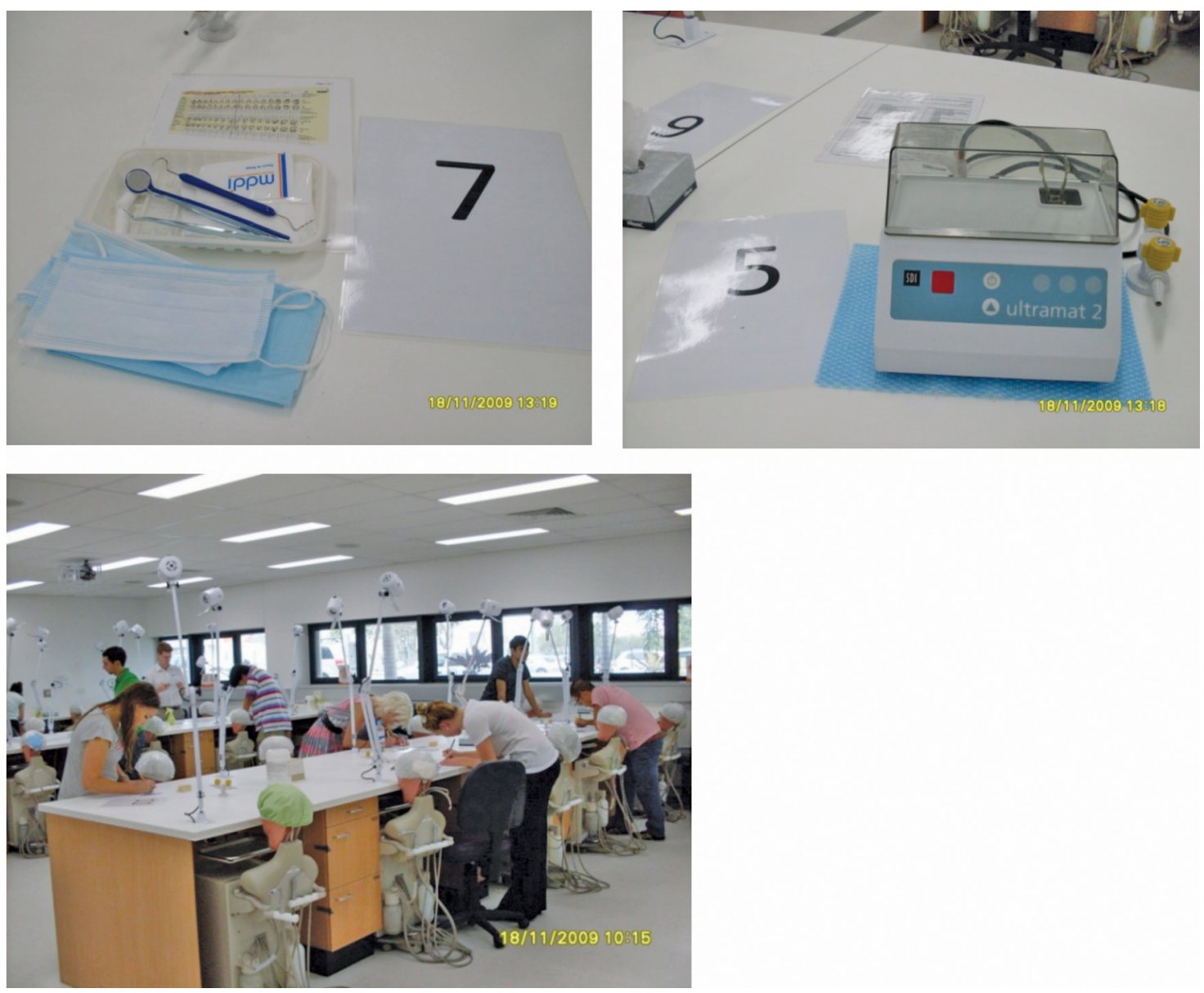

Figure 8. Twenty-station OSCE and simulation laboratory at Griffith University (1005DOH OSCE in November 2009)

care, and technical competence. ${ }^{14}$ Whether it actually does so is the subject of ongoing research.

\section{Future Directions}

Determining optimal strategies to assess students' capabilities is a challenge for all involved in dental education. ${ }^{26,29}$ In this case study, which spans our experience from 2004 to 2009, senior faculty members in the School of Dentistry and Oral Health have been continuously reviewing their own courses for alignment between the assessment method, the desired learning outcomes, and the overall values manifest in the school philosophy. A faculty-wide response is now due. Assessment of clinical skills in oral health therapy education could be more userfriendly in busy clinical settings where patient care is the first priority and student assessment often has to take second place. As identified by Norcini and Burch in 2007, low faculty participation in formative assessment and feedback strategies is the most significant limiting factor to improving the situation. ${ }^{34}$ Part-time faculty members, who teach a limited number of sessions and who have to leave their private practices to support the university in this way, often have particular challenges in this regard.

Two initiatives to enhance assessment in the School of Dental and Oral Health at Griffith University are now being implemented. These are the extension of time for clinical supervisors in the dental clinic and continuation of professional development and training for all faculty members, be they full-time or part-time. Part of the intent of these initiatives is to stimulate a broader, faculty-wide response. 
First, the director of clinical operations proposes to extend the sessions for clinical supervisors of dental and OHT students from three to four hours to allow thirty minutes of preclinic briefing time and thirty minutes of postclinic feedback time. This encourages greater participation of tutors in providing formative assessment and feedback and demonstrates a significant investment of financial and human resources in the development of professional competence for our dental and oral health students. ${ }^{34}$

Second, faculty development in learning, teaching, and assessment is being strengthened. ${ }^{37}$ As part of continuing professional development in the school, faculty members have continuing opportunities to participate in varied and regular formal opportunities for educational development. ${ }^{38,39}$ Examples include a full-day workshop funded by the Australian Learning and Teaching Council (ALTC), which will incorporate an "inspiration day" at a retreat to discuss learning, teaching, and assessment as teachers amongst teachers. Experts will be invited to lead the discussions and introduce some important topics. Within a relaxed and open environment, each faculty member will have the opportunity to contribute his or her own experience and exchange views with others. The aim for this process is to ensure that the faculty members will have information and inspiration to continue their pursuit of excellence in teaching. ${ }^{38,39}$

Beyond this inspiration day, senior management of the faculty has initiated projects that evaluate the quality of preclinical and clinical teaching reported here. It is expected that as the findings of the other initiatives are reported, other broader facultywide responses will follow.

\section{Conclusion}

This assessment case report documents the professional and clinical care values upon which Griffith University has centered its curriculum and assessments. In this way, it reasserts the value of clinical competence in recognizing the patient before the medical/dental condition or clinical intervention. Further, it seeks to demonstrate that this can be achieved by dental schools' adopting an approach of comprehensive care as its foundation for curriculum design and patient treatment. This approach helps guide teaching, learning, and assessment practices to approximate authentic general practice in the United States, Canada, the United Kingdom,
European countries, and Australia. The challenge for Griffith is to comprehensively evaluate and report on the effectiveness of the initiatives reported here. The challenge for dental schools more generally, including Griffith University, is to holistically assess the integrated learning outcomes of how students put it all together for the ultimate benefit of the patient. This article has illustrated how this is currently being addressed in one program at Griffith University as a guide to others wishing to emulate and further develop these approaches.

\section{REFERENCES}

1. Jones ML, Hobson RS, Plasschaert AJM, Gundersen S, Dummer P, Roger-Leroi V, et al. Quality assurance and benchmarking of dental education: an approach for European dental schools, 2006. At: http://dented.learnonline. $\mathrm{ie} / \mathrm{mod} / \mathrm{resource} / \mathrm{view} . \mathrm{php}$ ?id=306. Accessed: October 28, 2008.

2. Fendler F. Annual report: ADEA Section on Comprehensive Care and General Dentistry, 2008. At: www.adea.org/ about_adea/governance/Documents/2008AR_CCGD.doc. Accessed: November 23, 2009.

3. American Dental Education Association. ADEA competencies for the new general dentist. J Dent Educ 2010;74(7):765-8.

4. Evangelidis-Sakellson V. Student productivity under requirement and comprehensive care systems. J Dent Educ 1999;63(5):407-13.

5. American Dental Education Association. Sections and Special Interest Groups. At: www.adea.org/about_adea/ SectionsSIGs/Pages/ADEASectionsandSpecialInterestGroups.aspx. Accessed: November 23, 2009.

6. Cowpe J, Plasschaert AJM, Harzer W, Vinkka-Puhakka H, Walmsley AD. Profile and competencies for the graduating European dentist: update 2009. Birmingham, UK: Association for Dental Education in Europe, 2009.

7. The first five years: a framework for undergraduate dental education, $2^{\text {nd }}$ ed. London: General Dental Council, August 2002.

8. Boyd MA, Gerrow JD, Chambers DW, Henderson BJ. Competencies for dental licensure in Canada. J Dent Educ 1996;60(10):842-6.

9. American Association of Dental Schools. Competencies for the new dentist. J Dent Educ 1997;71(7):556-8.

10. Hendricson W. Appropriate assessments for competencybased education. At: www.adea.org/adeacci/CampusLiaisons/Liaison-Ledger/GuestPerspective/Pages/ November2008CCIGuestPerspective.aspx. Accessed: November 23, 2009.

11. Dentist labour force in Australia, 2005. Adelaide: Australian Institute of Health and Welfare Dental Statistics and Research Unit, July 2008.

12. Dental therapist labour force in Australia, 2005. Adelaide: Australian Institute of Health and Welfare Dental Statistics and Research Unit, July 2008.

13. Licari FW, Chambers DW. Some paradoxes in competency-based dental education. J Dent Educ 2008;72(1):8-18. 
14. Johnson NW. The ten commandments for curriculum development. Southport, Australia: Griffith University, November 2005.

15. School of Dentistry and Oral Health, Griffith University. Programs and courses. At: www.griffith.edu.au/health/ school-dentistry-oral-health/programs-courses. Accessed: April 19, 2010.

16. Dental Board of Queensland. Code of practice \#1 practice of dentistry by dental therapists and dental hygienists. Brisbane: Dental Board of Queensland, 2006:1-4.

17. Creating an interprofessional learning environment through communities of practice: an alternative to traditional preceptorship. Calgary: Health Canada, 2009.

18. School of Dentistry and Oral Health, Griffith University. At: www.griffith.edu.au/health/school-dentistry-oralhealth. Accessed: April 19, 2010.

19. Evans J, Johnson NW, Henderson A. The future of education and training in dental technology: designing a dental curriculum that facilitates teamwork across the oral health professions. Br Dent J 2010;208:227-30.

20. School of Dentistry and Oral Health, Griffith University. Bachelor of oral health in oral health therapy, Gold Coast. At: www17.griffith.edu.au/cis/p_cat/require.asp?ProgCo $\mathrm{de}=1262 \&$ Type $=$ structure. Accessed: July 19, 2009.

21. World Health Organization. Framework for action on interprofessional education and collaborative practice. Geneva: World Health Organization, 2010.

22. Kroon J. Summary of community research placement 2 (Griffith University). At: www3.griffith.edu.au/03/STIP4/ app?page $=$ CourseEntry\&service $=$ external $\&$ sp $=$ S3015D OH_Y2. Accessed: July 16, 2009.

23. Johnson NW, Kroon J. Community research placements in oral health teaching: the Griffith experience. Presentation at International Association for Dental Research Conference, 2010, Barcelona, Spain.

24. Lalloo R, Johnson NW, Mackay J, Foster R. A clinical experience in remote Australia: student feedback. Presentation at International Association for Dental Research Conference, 2010, Barcelona, Spain.

25. Mattheos N, Foster L, Oberholzer T. A novel team-based concept of treatment planning for training in the comprehensive care clinic. Presentation at 35th Congress of the Association for Dental Education in Europe, August 2009, Helsinki, Finland.

26. Wass V, Van der Vleuten C, Shatzer J, Jones R. Assessment of clinical competence. Lancet 2001;357(9260):945-9.

27. Miller GE. The assessment of clinical skills/competence/ performance. Acad Med 1990;65(9 Suppl):s63-s67.

28. Jolly B. Innovative assessment. Presentation at 13 th Ottawa International Conference on Clinical Competence, March 5-8, 2008, Melbourne, Australia.

29. Albino JE, Young SK, Neumann LM, Kramer GA, Andrieu SC, Henson L, et al. Assessing dental students' competence: best practice recommendations in the perfor- mance assessment literature and investigation of current practices in predoctoral dental education. J Dent Educ 2008;72(12):1405-35.

30. Young S, Albino J, Neumann L, Kramer G, Andrieu SC, Henson L, et al. What methods do dental school course directors use to assess students' progress toward competence? Selected results of the 2008 student competency assessment survey. Presentation at American Dental Education Association Commission on Change and Innovation in Dental Education Liaisons Summer Conference, June 23-25, 2008, Chicago, IL.

31. Divaris K, Barlow PJ, Chendea SA, Cheong WS, Dounis A, Dragan IF, et al. The academic environment: the students' perspective. Eur J Dent Educ 2008;12(Suppl 1): 120-30.

32. Hendricson WD. What methods do dental school course directors use to assess students' progress toward competency? Washington, DC: American Dental Education Association, 2008. At: www.adea.org/adeacci/Resources/ Documents/Competency_Assessment_Findings-Hendricson.pdf. Accessed: November 23, 2009.

33. Short LM, Evans J, Mackay J, Johnson NW, Nulty DD, Evelyn E. In: Tsang AKL, ed. Oral health therapy programs in Australia and New Zealand. Gold Coast, Australia: Knowledge Book \& Software, 2010.

34. Norcini J, Burch V. Workplace-based assessment as an educational tool: AMEE guide no. 31. Med Teacher 2007;29(9-10):855-71.

35. Evelyn E. Summary of 3017DOH_Y1: comprehensive oral health care 2 (Griffith University). At: www3.griffith. edu.au/03/STIP4/app?page $=$ CourseEntry\&service $=$ exter nal\&sp=S3017DOH_Y1. Accessed: February 2, 2010.

36. Schoonheim-Klein ME, Habets LLMH, Aartman IHA, van der Vleuten CP, Hoogstraten J, van der Velden U. Implementing an objective structured clinical examination (OSCE) in dental education: effects on students' learning strategies. Eur J Dent Educ 2006;10:226-35.

37. Hendricson WD, Anderson E, Andrieu SC, Chadwick DG, Cole JR, George MC, et al. Does faculty development enhance teaching effectiveness? J Dent Educ 2007;71(12):1513-33.

38. Mattheos N. Building university leadership capacity in the teaching of implant dentistry to dental students and local professional communities. Sydney: Australian Learning and Teaching Council, Grants and Projects, 2010. At: www.altc.edu.au/project-building-university-leadershipcapacity-implant-dentistry-griffith-2009. Accessed: November 9, 2010.

39. Mattheos N. Building university leadership capacity in the teaching of implant dentistry to dental students and local professional communities. Sydney: Australian Learning and Teaching Council, 2010. At: www.altc.edu.au/ project-building-university-leadership-capacity-implantdentistry-griffith-2009. Accessed: February 15, 2010. 